\title{
An exploration study to find important factors in market entrance: A case study of truck industry
}

\author{
Zoheir Khodamoradi, Naser Azad* and Seyed Mohsen Seyed Aliakbar
}

Department of Management, Islamic Azad University, South Tehran Branch, Tehran, Iran

\section{H R O N I C L E}

Article history:

Received May 12, 2013

Received in revised format

25 June 2013

Accepted 10 August 2013

Available online

August 122013

Keywords:

Truck industry

Factor analysis

Entering the market

Adaptation industry

\section{Introduction}

One of the most important issues on entering market activities is to find appropriate business product to enter (Javalgi et al., 2011). There are literally various research studies associated with market entrance. Shieh and Wu (2012), for instance, concentrated on equity-based entry mode choices adopted by multinational corporations (MNCs) in the Greater Chinese Economic Area (GCEA) for entering Vietnam as a new growing market. They reported that equity-based entry modes were significant when foreign direct investments (FDI) firms entering Vietnam originate from the GCEA, which includes Mainland China, Hong Kong, Taiwan, and Singapore. However, the interaction results indicated that industry did not have a moderating impact on the relationship between location and entry mode, whereas it was not found that industrial cluster was specific to any one location. The generalized model had implications for the theoretical and managerial perspectives of both the host and the home countries.

\footnotetext{
*Corresponding author.

E-mail address: dr.naserazad@yahoo.com (N. Azad)

\begin{abstract}
This paper presents an empirical investigation to find important factors influencing market penetration in truck industry. The proposed study designs a questionnaire in Likert scale consists of 51 questions, distributes it among 300 people who worked for different truck industry related units and collects 262 filled ones. Cronbach alpha is calculated as 0.89. In addition, Kaiser-Meyer-Olkin Measure of Sampling Adequacy and Approx. Chi-Square are 0.845 and 3067.443, respectively. The study has implemented principal component analysis and the results have indicated that there were eight factors influencing entering truck making industry including adaptation strategies, new ideas, cost competitiveness, product capabilities, market characteristics, competition threats from external market environment and export accelerators.
\end{abstract}


Xie et al. (2011) adopted the "strategy tripod” perspective, which integrates resource-, industry-, and institution-based perspective to study foreign firms' strategic positioning (i.e. their choice of generalist or specialist strategy) in the U.S. host market. The findings of their study supported the major hypotheses, recommending that: (1) market concentration and foreign firms' heterogeneous resources influence foreign firms' strategic positioning; (2) institutional distance between host and home countries exerts confounding moderating influences on the relationship between firm resources and strategic positioning in the host market. Otto (2008) provided a system dynamics model as a decision help in assessing and communicating complex market entry strategies.

Slangen and van Tulder (2009) investigated on two factors of culture and political issues on entry market and reported that cultural distance had no impact on entry mode choice and that political risk had the weakest influence of all aspects of governance quality. Czinkota et al. (2009) concentrated on developing, measuring, and empirically examining a framework of essential factors influencing international market entry mode choice of U.S. business schools by applying primary data from faculty and administrators of U.S. Master of Business Administration (MBA) schools.

Chang et al. (2012) hypothesized that governance quality plays a contingent role on market entrance. Chen and Chang (2011) built a panel data set and made a dynamic probit analysis on the mode choice between wholly-owned subsidiaries and joint ventures. They reported that state dependence between current and past modes played an essential role in determining entry mode choice. Zhou (2007) investigated the impacts of entrepreneurial proclivity and foreign market knowledge on early internationalization.

Rodríguez-Pinto et al. (2011) examined the role of market entry order as a moderator of the mediating effects of innovation speed and product quality on the MO-NP performance relationship. They reported that the performance of first-to-market products, early entrants, and late movers was associated with the specific implementation that firms make of its MO, whether it was developing high-quality products or accelerating innovation speed.

Morschett et al. (2010) investigated the external antecedents of the choice of entry mode by metaanalyzing data from 72 independent primary studies. They concentrated on the decision between wholly owned subsidiaries and cooperative entry modes. They found a strong positive relationship between power distance as a cultural trait of the firm's home country and the propensity to establish a wholly owned subsidiary.

Malhotra et al. (2011) performed a comparative analysis of the role of national culture on foreign market acquisitions by US firms and firms from emerging countries. Pehrsson discussed different strategy antecedents of modes of entry into foreign markets. Ellis (2007) investigated whether market distant could be serious problem for market entry or not in terms of penetrating into international market. Quer et al. (2007) provided new empirical evidence that cultural distance could reduce the likelihood of choosing equity entry modes, while firm profitability and internal financial funds availability favour the assumption of greater commitment in the international expansion process.

\section{The proposed study}

This paper presents an empirical investigation to find important factors influencing entering truck industry. The proposed study designs a questionnaire in Likert scale consists of 51 questions, distributes it among 300 people who worked for different business units and collects 262 filled ones. Cronbach alpha is calculated as 0.89. In addition, Kaiser-Meyer-Olkin Measure of Sampling Adequacy and Approx. Chi-Square are 0.845 and 3067.443, respectively. During the study, we have decided to remove six questions in order to make sure there is no strong correlation among questions and determinant is not equal to zero. Table 1 summarizes the results of our survey. 
Table 1

The summary of principal component analysis

\begin{tabular}{|c|c|c|c|c|c|c|c|c|c|}
\hline \multirow{2}{*}{ Component } & \multirow{2}{*}{\multicolumn{3}{|c|}{$\begin{array}{l}\text { Initial Eigenvalues } \\
\% \text { of Variance } \quad \text { Cumulative \% }\end{array}$}} & \multicolumn{3}{|c|}{ Extraction Sums of Squared Loadings } & \multicolumn{3}{|c|}{ Rotation Sums of Squared Loadings } \\
\hline & & & & Total & $\%$ of Variance & Cumulative \% & Total & \% of Variance & Cumulative \% \\
\hline 1 & 8.608 & 19.564 & 19.564 & 8.608 & 19.564 & 19.564 & 2.767 & 6.288 & 6.288 \\
\hline 2 & 2.512 & 5.709 & 25.272 & 2.512 & 5.709 & 25.272 & 2.633 & 5.985 & 12.272 \\
\hline 3 & 1.852 & 4.209 & 29.482 & 1.852 & 4.209 & 29.482 & 2.448 & 5.563 & 17.835 \\
\hline 4 & 1.619 & 3.680 & 33.161 & 1.619 & 3.680 & 33.161 & 2.169 & 4.929 & 22.764 \\
\hline 5 & 1.474 & 3.351 & 36.512 & 1.474 & 3.351 & 36.512 & 2.000 & 4.545 & 27.309 \\
\hline 6 & 1.405 & 3.192 & 39.704 & 1.405 & 3.192 & 39.704 & 1.929 & 4.384 & 31.693 \\
\hline 7 & 1.350 & 3.069 & 42.773 & 1.350 & 3.069 & 42.773 & 1.915 & 4.352 & 36.045 \\
\hline 8 & 1.308 & 2.972 & 45.745 & 1.308 & 2.972 & 45.745 & 1.827 & 4.153 & 40.198 \\
\hline 9 & 1.218 & 2.768 & 48.514 & 1.218 & 2.768 & 48.514 & 1.803 & 4.099 & 44.296 \\
\hline 10 & 1.166 & 2.649 & 51.163 & 1.166 & 2.649 & 51.163 & 1.775 & 4.035 & 48.331 \\
\hline 11 & 1.154 & 2.622 & 53.785 & 1.154 & 2.622 & 53.785 & 1.716 & 3.901 & 52.232 \\
\hline 12 & 1.050 & 2.387 & 56.172 & 1.050 & 2.387 & 56.172 & 1.473 & 3.347 & 55.579 \\
\hline 13 & 1.021 & 2.321 & 58.493 & 1.021 & 2.321 & 58.493 & 1.282 & 2.914 & 58.493 \\
\hline 14 & .976 & 2.218 & 60.711 & & & & & & \\
\hline 15 & .946 & 2.150 & 62.861 & & & & & & \\
\hline 16 & .928 & 2.110 & 64.971 & & & & & & \\
\hline 17 & .877 & 1.994 & 66.965 & & & & & & \\
\hline 18 & .868 & 1.972 & 68.936 & & & & & & \\
\hline 19 & .842 & 1.913 & 70.849 & & & & & & \\
\hline 20 & .790 & 1.795 & 72.644 & & & & & & \\
\hline 21 & .762 & 1.732 & 74.376 & & & & & & \\
\hline 22 & .730 & 1.660 & 76.035 & & & & & & \\
\hline 23 & .719 & 1.634 & 77.670 & & & & & & \\
\hline 24 & .693 & 1.575 & 79.245 & & & & & & \\
\hline 25 & .660 & 1.500 & 80.745 & & & & & & \\
\hline 26 & .647 & 1.470 & 82.215 & & & & & & \\
\hline 27 & .629 & 1.429 & 83.644 & & & & & & \\
\hline 28 & .578 & 1.313 & 84.957 & & & & & & \\
\hline 29 & .564 & 1.282 & 86.239 & & & & & & \\
\hline 30 & .551 & 1.253 & 87.492 & & & & & & \\
\hline 31 & .523 & 1.189 & 88.681 & & & & & & \\
\hline 32 & .512 & 1.164 & 89.845 & & & & & & \\
\hline 33 & .478 & 1.087 & 90.932 & & & & & & \\
\hline 34 & .452 & 1.027 & 91.959 & & & & & & \\
\hline 35 & .434 & .987 & 92.946 & & & & & & \\
\hline 36 & .420 & .954 & 93.900 & & & & & & \\
\hline 37 & .397 & .902 & 94.802 & & & & & & \\
\hline 38 & .386 & .878 & 95.681 & & & & & & \\
\hline 39 & .370 & .840 & 96.520 & & & & & & \\
\hline 40 & .351 & .799 & 97.319 & & & & & & \\
\hline 41 & .341 & .774 & 98.093 & & & & & & \\
\hline 42 & .310 & .705 & 98.798 & & & & & & \\
\hline 43 & .275 & .625 & 99.423 & & & & & & \\
\hline 44 & .254 & .577 & 100.000 & & & & & & \\
\hline
\end{tabular}

Next, we need to extract important components from the study of this paper. Fig. 1 demonstrates the summary of Scree plot. As we can observe from the results of Fig. 1 and Table 1, there are 13 components with relative Eigenvalue of greater than one. We have computed the communalities with all 44 and Table 2 demonstrates the summary of our results. Finally, we have extracted eight factors out of 13 factors and they are explained in next section. 


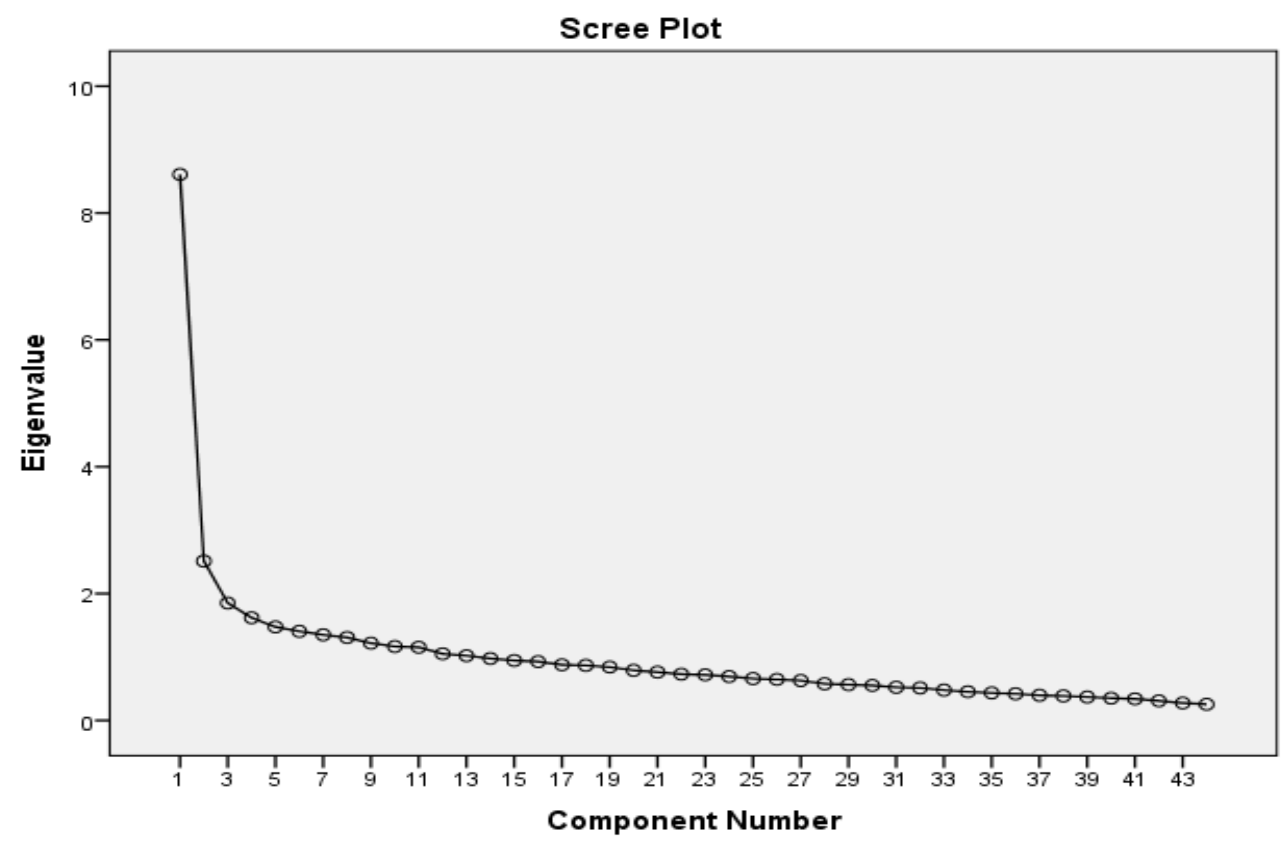

Table 2

Fig. 1. The summary of Scree plot

The summary of communities

\begin{tabular}{|c|c|c|c|}
\hline Variable & Com. & Variable & Com. \\
\hline Dynamic of industry & .471 & Financial resources & .530 \\
\hline Competitive circumstances & .523 & Organizational learning & .613 \\
\hline Marketing expenditures & .434 & Rate of entrance & .639 \\
\hline Distribution network & .636 & Size of investment & .625 \\
\hline Demand fluctuation & .608 & Government rules & .622 \\
\hline Sales growth & .583 & Risk & .574 \\
\hline Advertisement density & .638 & Political danger & .687 \\
\hline Competitors & .608 & International experience & .632 \\
\hline Human resources & .600 & Kind of product & .609 \\
\hline Commitment to market & .610 & Product distinction & .631 \\
\hline Danger in competition & .524 & Performance of new products & .562 \\
\hline Knowledge on foreign market & .637 & New product development & .657 \\
\hline Quality of services & .542 & New innovations & .580 \\
\hline Quality of products & .591 & Order from foreign market & .463 \\
\hline Product price & .587 & Motivation for competition & .582 \\
\hline Capability to build connection with market & .684 & Market structure & .564 \\
\hline Technical capabilities & .604 & Market size & .596 \\
\hline Marketing skills & .566 & Market growth rate & .592 \\
\hline Management skills & .623 & Market potential & .587 \\
\hline Firm reputation & .516 & Deregulation policies & .644 \\
\hline Research \& Development & .571 & distance from market & .462 \\
\hline Export & .531 & Board of director & .600 \\
\hline
\end{tabular}

\section{The results}

In this section, we present details of our findings eight detected factors, which are summarized in Table 3 as follow, 
Table 3

The summary of factor analysis

\begin{tabular}{|c|c|c|c|c|c|}
\hline Factor & Measurable variable & Weight & 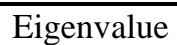 & Variance & Accumulated \\
\hline \multirow{5}{*}{ Firm activities } & Advertisement density & 0.712 & 8.608 & 6.288 & 6.288 \\
\hline & Firm reputation & 0.574 & & & \\
\hline & Sales growth & 0.572 & & & \\
\hline & Research \& development density & 0.422 & & & \\
\hline & Risk & 0.408 & & & \\
\hline \multirow{4}{*}{ Adaptability } & Commitment to market & 0.690 & 2.512 & 5.985 & 12.272 \\
\hline & Product quality & 0.633 & & & \\
\hline & Market deregulation & 0.527 & & & \\
\hline & Export & 0.340 & & & \\
\hline \multirow{4}{*}{ New ideas } & New product development & 0.772 & 1.852 & 5.563 & 17.835 \\
\hline & Innovation speed & 0.629 & & & \\
\hline & Orders from outside country & 0.434 & & & \\
\hline & Dynamic of industry & 0.331 & & & \\
\hline \multirow{4}{*}{ Competitive price } & Price of product & 0.674 & 1.619 & 4.929 & 22.764 \\
\hline & Marketing expenditure & 0.505 & & & \\
\hline & Market growth & 0.451 & & & \\
\hline & Market potential & 0.349 & & & \\
\hline \multirow{4}{*}{ Product capabilities } & Exclusive product & 0.629 & 1.619 & 4.929 & 27.309 \\
\hline & Performance of new product & 0.608 & & & \\
\hline & Type of product & 0.449 & & & \\
\hline & Technical capability of firm & 0.379 & & & \\
\hline \multirow{5}{*}{ Competitive market } & Competition opportunities & 0.572 & 1.308 & 4.153 & 40.198 \\
\hline & Financial resources & 0.564 & & & \\
\hline & Competitors & 0.440 & & & \\
\hline & Competition motivation & 0.402 & & & \\
\hline & Market size & 0.363 & & & \\
\hline \multirow{4}{*}{$\begin{array}{l}\text { Threats from } \\
\text { foreign firms }\end{array}$} & Government rules \& regulations & 0.675 & 1.218 & 4.099 & 44.296 \\
\hline & Political dangers & 0.641 & & & \\
\hline & Distance to market & 0.358 & & & \\
\hline & Market structure & 0.348 & & & \\
\hline \multirow{4}{*}{ Market accelerators } & Rate of entrance & 0.731 & 1.166 & 4.035 & 48.331 \\
\hline & Size of investment & 0.516 & & & \\
\hline & Organizational learning & 0.512 & & & \\
\hline & Demand fluctuation & 0.335 & & & \\
\hline
\end{tabular}

As we can observe from the results of Table 3, there are eight factors associated with the proposed study including firm activities, adaptability, new ideas, competitive price, product capabilities, competitive market, threats from foreign firms and market accelerators.

\section{Discussion and conclusion}

In this survey, we have performed an investigation on measuring the impact of various factors on market entrance in truck industry in Iran. The study has implemented principal component analysis and the results have indicated that there were eight factors influencing market entrance including, firm activities, adaptability, new ideas, competitive price, product capabilities, competitive market, threats from foreign firms and market accelerators.

In terms of firm activity, there are six sub-components including advertisement density, firm reputation, sales growth, research \& development density and risk advertisement density is the most important sub-factor followed by firm reputation. The second factor, adaptability, consists of four factors including commitment to market, product quality, market deregulation and export. In this group commitment to market is the most influential factor. The third factor, new ideas, consists of five factors where new product development is the most important item. The fourth factor is 
associated with competitive price with four sub-components where price of product is the most important item. Product capabilities is the next item with four items and exclusive product is the most influential one. The other factors are playing essential role and must be considered for market entrance.

\section{Acknowledgment}

The authors would like to thank the anonymous referees for their construction comments on earlier version of this work.

\section{References}

Chang, Y. C., Kao, M. S., Kuo, A., \& Chiu, C. F. (2012). How cultural distance influences entry mode choice: The contingent role of host country's governance quality. Journal of Business Research, 65(8), 1160-1170.

Chen, M. Y., \& Chang, J. Y. (2011). The choice of foreign market entry mode: An analysis of the dynamic probit model. Economic Modelling, 28(1), 439-450.

Czinkota, M. R., Grossman, D. A., Javalgi, R. R. G., \& Nugent, N. (2009). Foreign market entry mode of service firms: The case of US MBA programs. Journal of World Business, 44(3), 274286.

Ellis, P. D. (2007). Paths to foreign markets: does distance to market affect firm internationalisation?. International Business Review, 16(5), 573-593.

Javalgi, R. R. G., Deligonul, S., Dixit, A., \& Cavusgil, S. T. (2011). International market reentry: A review and research framework. International Business Review, 20(4), 377-393.

Malhotra, S., Sivakumar, K., \& Zhu, P. (2011). A comparative analysis of the role of national culture on foreign market acquisitions by US firms and firms from emerging countries. Journal of Business Research, 64(7), 714-722.

Morschett, D., Schramm-Klein, H., \& Swoboda, B. (2010). Decades of research on market entry modes: what do we really know about external antecedents of entry mode choice?. Journal of International Management, 16(1), 60-77.

Otto, P. (2008). A system dynamics model as a decision aid in evaluating and communicating complex market entry strategies. Journal of Business Research, 61(11), 1173-1181.

Pehrsson, A. (2008). Strategy antecedents of modes of entry into foreign markets. Journal of Business Research, 61(2), 132-140.

Quer, D., Claver, E., \& Andreu, R. (2007). Foreign market entry mode in the hotel industry: The impact of country-and firm-specific factors. International Business Review, 16(3), 362-376.

Rodríguez-Pinto, J., Carbonell, P., \& Rodríguez-Escudero, A. I. (2011). Speed or quality? How the order of market entry influences the relationship between market orientation and new product performance. International Journal of Research in Marketing, 28(2), 145-154.

Shieh, B. L., \& Wu, T. C. (2012). Equity-based entry modes of the Greater Chinese Economic Area's foreign direct investments in Vietnam. International Business Review, 21(3), 508-517.

Slangen, A. H., \& van Tulder, R. J. (2009). Cultural distance, political risk, or governance quality? Towards a more accurate conceptualization and measurement of external uncertainty in foreign entry mode research. International Business Review, 18(3), 276-291.

Xie, Y. H., Zhao, H. J., Xie, Q. J., \& Arnold, M. (2011). On the determinants of post-entry strategic positioning of foreign firms in a host market: A "strategy tripod" perspective. International Business Review, 20(4), 477-490.

Zhou, L. (2007). The effects of entrepreneurial proclivity and foreign market knowledge on early internationalization. Journal of World Business, 42(3), 281-293. 